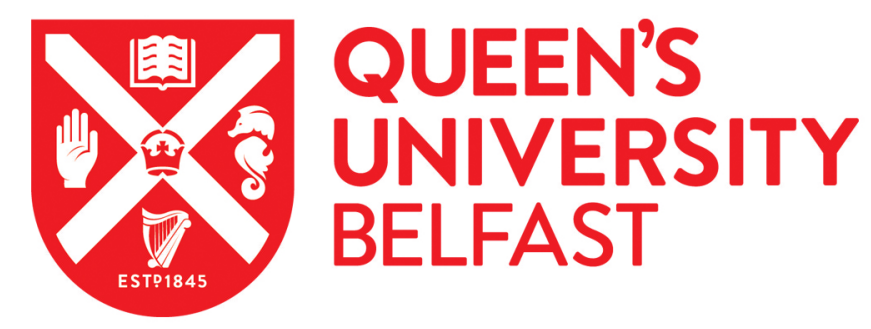

\title{
Failing worse? Science, security and the birth of a border technology
}

Lisle, D. (2018). Failing worse? Science, security and the birth of a border technology. European Journal of International Relations, 24(4), 887-910. https://doi.org/10.1177/1354066117738854

\author{
Published in: \\ European Journal of International Relations
}

\section{Document Version:}

Peer reviewed version

Queen's University Belfast - Research Portal:

Link to publication record in Queen's University Belfast Research Portal

Publisher rights

(C) The Author(s) 2017. This work is made available online in accordance with the publisher's policies. Please refer to any applicable terms of use of the publisher.

\section{General rights}

Copyright for the publications made accessible via the Queen's University Belfast Research Portal is retained by the author(s) and / or other copyright owners and it is a condition of accessing these publications that users recognise and abide by the legal requirements associated with these rights.

Take down policy

The Research Portal is Queen's institutional repository that provides access to Queen's research output. Every effort has been made to ensure that content in the Research Portal does not infringe any person's rights, or applicable UK laws. If you discover content in the Research Portal that you believe breaches copyright or violates any law, please contact openaccess@qub.ac.uk. 


\section{Failure Repurposed:}

In February 2014, the Science Gallery at Trinity College Dublin curated an exhibition entitled 'Fail Better' which told the stories of 'beautiful, heroic and instructive failures' (Science Gallery, 2014). Quite appropriately, the original manuscript pages of Samuel Beckett's Worstward Ho were displayed so visitors could see the development of his famous motto: 'Ever Tried. Ever Failed. No Matter. Try Again. Fail Again. Fail Better.' With the exception of a few instances of total failure (e.g. a centrifugal birth machine to spin mothers around and cause their babies to 'fly' out of the womb), the exhibition focused entirely on the stories of failure that eventually led to successful scientific and/or technological inventions. For example, James Dyson, the industrial designer who invented the bag-less Dyson vacuum cleaner, explained how it 'took him 5,127 prototypes to develop the final machine, each failed prototype informing the next one' (Dyson, 2014). Other designers, inventors and scientists detailed their own stages of failure before finally arriving at a successful final product (e.g. the Raspberry Pi computer, the K1 disposable syringe, and the suspension on a Formula 1 Ferrari) (Science Gallery, 2014). As the curators made clear, they were interested in the positive aspects of failure - 'the role of failure in stimulating creativity: in learning, in science, engineering and design' (Science Gallery, 2014). This understanding of failure as instructive is currently flourishing in places like Silicon Valley where Beckett's original motto has been re-booted into the mantra of Start Up companies: 'Fail fast, fail early, fail often'. For investors, entrepreneurs, and software developers, failure is now absolutely central to inventing and commercializing new technologies (Basulto, 2012; Schumpeter, 2011). Rather than an experience to be avoided, failure is now understood as the key to success: 
The entrepreneurial fashion for failure ... is not really

concerned, as Beckett was, with failure per se - with the

necessary defeat of every human endeavour, of all efforts at

communication, and of language itself — but with failure as an

essential stage in the individual's progress toward lucrative self-

fulfilment. Failure, in the \#failbetter sense, is something to be

embraced and celebrated, to be approached with a view to

understanding how it might most effectively be transmuted into

success (O’ Connell, 2014).

By jettisoning the dark clutches of an absurd and unforgiving universe - the usual Beckettian milieu - entrepreneurs, scientists, inventors, researchers, policy-makers, athletes and artists are repurposing the 'Fail Better' motto as an inspirational rallying cry. Indeed, Beckett's quotation is available on mouse pads, iphone cases, tee-shirts, mugs, keychains, fridge magnets, and on a variety of motivational posters with tasteful frames and designer fonts. Swiss tennis player Stan Wawrinka has it tattooed on his left forearm. Stripped of its original misanthropic overtones, this repurposed account of \#failbetter has made its way outside of Silicon Valley and is currently shaping organizational change in government, science, higher education, business, media, and the military (Baumard \& Starbuck, 2005; Cannon \& Edmunson, 2005). Embedded in this transformation is a particular kind of resilient disposition needed to withstand the experience of failure and turn it into success: an inexhaustible spirit of hard work, an ability to reflect on the difficulties you encounter, the willingness to learn from your mistakes, and the determination to overcome hardship and misfortune. We should not be surprised, then, that \#failbetter is currently energizing Neoliberal leaders across the 
world who encourage employees, citizens and consumers to cultivate resilience so they can 'bounce-back' from failure.

Seeking to recover some of the darkness of Beckett's original claim, this paper contests the repurposing of failure into a singularly positive and instructive experience. It illustrates the reductive nature of this success / failure logic and seeks to develop a more heterogeneous and poly-vocal understanding of failure. I am particularly interested in failure's capacity to disrupt, re-work, surprise and deconstruct accepted modes of thinking and knowing - precisely the kind of energies Beckett was pondering in his invocation to fail better. He was not interested in those rare examples of failure that result in fruitful or even emancipatory new paradigms; indeed, even these have darkness within. Rather, he revelled in the much more common experiences of failure as permanent, painful and often unspeakable. I want to explore the political possibilities that emerge in that Beckettian terrain and ask whether a more heterogeneous account of failure might help contest the closures, exclusions and violence currently underscoring our political imaginaries.

This critical reimagining of failure has relevance across a range of pressing global issues, including our collective failures to address climate change, structural economic inequality and entrenched forms of violence. In this paper, I focus on and hope to develop a body of recent critical scholarship that has begun to think productively about the significance of failure for global politics; specifically, the failure of sophisticated border security technologies to accurately distinguish between that which is safe (e.g. normal, recognized, welcome) and that which is dangerous (e.g. deviant, other, unwelcome) (Amoore, 2011; 2013; Amicelle, Aradau \& Jeandesboz, 2015; De Goede \& Randalls, 2009; Leese, 2015; Magnet, 2011; Salter, 2014). This 
work illustrates how the blunt norm / deviant distinction driving border decisions cannot account for the diversity of behaviours and appearances presented for inspection, with the result that techno-scientific designations of unwanted bodies (e.g. irregular migrants, asylum seekers, refugees) and dangerous goods (e.g. explosives, poisons, drugs) end up reproducing prevailing social exclusions such as race, gender, class and sexuality (Amoore \& Hall, 2009; Browne, 2010; Magnet, 2011; Vukov, 2016; Wilcox, 2015: 104-130). Of particular interest to me in this body of work are examinations of the way failure is pre-emptively built into border security technologies. For example, adaptive algorithms autonomously utilize their own failures to learn, correct and re-tune so as to better track the changing nature of norm / deviant in real time (Amoore, 2009; Amoore \& Pioyukh, 2016; Amoore \& Raley, 2017; Aradau \& Blanke, 2015; Hall, 2018). In focusing on pre-emptive decision making, this literature asks challenging questions about who/what is actually making decisions at the border (the machine? the border guard?); where that decision is generated (the border crossing? the Cloud? the algorithm?); and who/what is therefore responsible when these decisions go wrong. Elongating border decisions in this way insists that to fully open the 'black box' of border security technology it is necessary to scrutinize the antecedent register of research and development - the life-worlds of technoscience where border security technologies are built and tested (Bourne, Johnson \& Lisle, 2015).

This paper spatially transposes insights about pre-emptively organized technological failure at the border back into the laboratories where such border technologies are built. While it aligns with critical analyses of how software developers pre-emptively imagine, construct and implement border decisions when designing algorithms (Amoore, 2013; Amoore \& Raley, 2017; Hall, 2018), this paper asks a more 
general question about how an instructive account of failure governs behaviour, relations, progress and outcomes in the antecedent border space of the laboratory. How do the congregation of experts engaged in the collective practice of developing a border security technology understand the possibilities and consequences of failure? How do they understand success? To what extent do their everyday practices in scientific laboratories proceed by repeated failures? Are there some failures that are acceptable in the course of research and development and others that are not? Who decides which failures matter and which don't, and how is that decision policed? To address these questions, this paper draws from an ethnographic study of a multi-sited, multinational and multi-institutional EU-funded project entitled Handhold (Handhold, 2012).

Handhold was one of several projects that received European funding to develop a portable, integrated device to detect CBRNE threats at borders that would be used 'by European customs agencies, border guards, first responders, police, civil security or others operating in potentially hostile environments' (Handhold, 2012). The overall goal of this device was to eventually replace the sniffer dog currently used in places like airports and sea ports. I was part of a team that was able to observe the work of Handhold up-close to gain insight into how technology develops in a security context (TRUST, 2013). ${ }^{1}$ We conducted multi-sited ethnographies, observations and interviews of the 9 major Handhold partners, and interacted with scientists, engineers, developers, entrepreneurs, managers and end-users from five different European countries. We were involved in Handhold throughout the central phase of its development, including the

\footnotetext{
${ }^{1}$ The 'Tracing Risk and Uncertainty in Security Technologies' (TRUST) project ran from March 2013October 2014. Working collectively and informed largely by Latour's (2005) approach to technology, five of us followed the Handhold project to see how the human and non-human actors collaborated together (TRUST, 2013). References to the TRUST interviews and observations are as follows: ENDU refers to End User interview; FOBS refers to Field Observation; MOBS refers to Meeting Observation; MREF refers to Meeting Reflections; and SE refers to Scientist / Engineer interview.
} 
important prototype test halfway through the project's lifespan. To get a broader sense

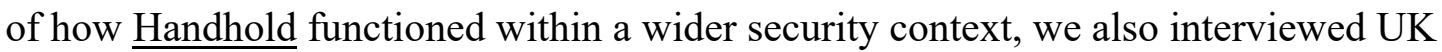
government scientists, engineers and managers who work at the interface of science, security and technology.

Throughout these investigations, I became interested in the strange and elusive accounts of failure articulated by funders, civil servants, scientists, engineers, entrepreneurs and end-users. Failure was simultaneously everywhere and nowhere: it drove practice and behaviour with a silent force, but it was seldom articulated in any tangible way. The more time I spent observing Handhold, the more I was able to discern a powerful consensus about what kind of failure is deemed acceptable - and even desirable - during the design and building of a border security technology. Overwhelmingly, the construction of the Handhold device was governed by an instructive account of failure that resonated with the Science Gallery's 2014 narrative: the participants in Handhold wanted to fail better. I'm particularly interested in the normative infrastructure embedded in that desire, and the way it governs scientific practice and imagination. During my observations of Handhold, I was struck by the linear, unidirectional and progressive learning trajectory that underscored this dominant understanding of failure and shaped the way scientists and engineers did their work. All, to a greater or lesser degree, obeyed the formula of 'experiment $\rightarrow$ fail $\rightarrow$ adapt $\rightarrow$ learn $\rightarrow$ re-try $\rightarrow$ succeed', and thus reaffirmed the story of scientific progress that is always told in hindsight: 'I failed in this way, several times, but then I adapted, learned, and my failures ultimately ended in success'. Reflecting on the Science Gallery's account of \#failbetter, I came to think of this formula as 'the Dyson narrative'. 
Using the construction of the Handhold device as a case study, this paper shows how an instructive account of failure (and the singular trajectory of learning embedded within it) governs the daily routines of scientists and engineers building the device, helps them avoid the 'wrong' kind of failures, and encourages them to pursue the 'right' kind of success. While not wishing to disavow this task, I am - rather unsurprisingly more interested in the failure of this instructive account of failure to govern scientific practice and imagination. I want to look at all the disturbing, awkward, surprising, disruptive, unexpected, painful and difficult experiences of failure that did not map onto the Dyson narrative. Part of the problem with an exclusive focus on the disciplining character of instructive failure is that it silences the creative agency of the scientists and engineers on Handhold. Certainly these figures were governed by an instructive account of failure, and spent enormous amounts of energy and emotional labour trying to live up to its dictates. But they were also irritated by it, reflexive about its power, and often emboldened to disobey its regulations. It was precisely these moments of resistance that allowed me to glimpse a subterranean universe of multiple failures that kept bubbling up in the everyday work of the Handhold participants. Indeed, I became fascinated with the disobedience of the scientists and engineers, and the alternative experiences of failure that their impiety made visible.

To explore the experiences of failure that do not fit the Dyson narrative, I draw from excellent critical work in Science, Technology and Society (STS) that deconstructs the myth of science as rational, ordered and instrumental (Barad, 2007; Haraway, 2016; Mol, 2003; Latour, 1979, 1987). By paying close attention to how the complex lifeworlds of scientists-in-action are intimately entangled with their materials, tools and methods, this literature reveals the idiosyncratic, unexpected and thoroughly messy 
ways that science actually solves problems. This critical framework is necessary for my analysis of Handhold because it enables me to think about the agency of failure - the work that it does in the world to guide practice, change behaviour, re-calibrate relations, alter materialities and mobilize futures. Using STS as a guide, then, this paper unfolds by examining how an instructive account of failure - the Dyson narrative - is obeyed and contested in the daily practices of research, discovery and collaboration as scientists and engineers struggle to build a border security device. I'm particularly interested in how non-productive experiences of failure made themselves felt at every stage in Handhold's development, leaking into the daily practices of scientists and engineers, shaping the manner in which they calculated risk, and haunting their relentless pursuit of innovation. Telescoping out of the specific case of Handhold, I end the paper by asking how more heterogeneous accounts of failure such as those articulated by creative artists might open up new political possibilities for thinking about science, security, technology and borders. These artful insights offer important clues for how we might conceptualize scientific failure outside of the Dyson narrative and instead attune ourselves to Beckett's insistence that failure can never be solved, overcome or dispensed with.

\section{Unacknowledged Failure: the everyday practice of science}

Failure is currently animating an important debate within scientific communities as they discuss the need to talk more openly about their failures and share data from failed experiments so that others will not repeat the same mistakes (Firestein, 2015; Vallery, 2016; Zaringhalam, 2016). Given the widespread nature of this debate, I expected to hear the Handhold scientists and engineers talk openly about their 
experiences of failure. What surprised me in the interviews and observations was that the centrality of failure to scientific practice was so widely accepted that it operated as common sense: it was both omnipresent and almost entirely unacknowledged. Indeed, Handhold participants met my questions about failure with expressions of surprise, bafflement and confusion. Why was I even interested in failure? Why does it matter? Why would I even want to know about it? This bewilderment was curious rather than hostile: for scientists and engineers, failure is simply an intrinsic part of everyday practice (i.e. you experiment, you fail, you adapt, you learn, you re-try and then hopefully you succeed). As one senior scientist / engineer with extensive experience on defence and security related projects explained: 'The usual approach of a scientist...is to fail, yeah? Success is a summation, an addition of failure... the standard process is failures' (SE22). Another scientist / engineer happily explained the routine process of continuously writing, failing and re-writing the project software as 'good practice': 'I expected it to be like this... this is the normal life of things', and after laughing quietly for a moment; 'technology never works when you want it to' (SE5). Similarly, a quite junior scientist / engineer demonstrated how the routinization of failure in everyday practice was the only way to make progress: 'sometimes it works, sometimes it doesn't... if something doesn't work you have still learned something, and you can help others' (SE6). The omnipresence of failure in the building of the Handhold device meant that even when it was at the prototype stage, all the participants expected it to fail. As one senior scientist / engineer wearily explained: 'No matter how hard you try something always goes wrong, because it is technology' (SE23; MREF5). For the scientists and engineers of Handhold, failure was so deeply embedded in their daily routines and practices that it effectively disappeared from view. To make any progress 
at all on their part of the device, all of them accepted a large degree of failing along the way; indeed, they understood failure as one of the principle drivers for learning, adaptation, solution and innovation.

In observing and listening to the scientists and engineers on $\underline{\text { Handhold, it became }}$ clear that their common sense understanding of failure was very much the Dyson narrative: they accepted failure because it would eventually lead to success. To try and dig underneath that common sense view, I became interested in research experiences on Handhold that disrupted this overly instructive pathway of failure. In other words, I started thinking about the mistakes, dead-ends, stupid ideas, whims, unrealized dreams, wasted efforts, false steps, aborted trajectories and breakdowns that nobody talks about. Some of that silence was broken during discussions about research publications. All scientists and engineers on the project, from the most senior Professor to the most junior PhD student, were very candid about how they actively wrote out non-productive failures from their published results (SE1; SE2; SE6). It wasn't that the troubling, difficult and often painful mistakes that constitute the messy ground of scientific exploration were absent from this project; it was that these awkward experiences were deliberately evacuated from the published record because they did not fit the Dyson narrative. This reveals some of the active work that an instructive account of failure actually does in constituting the epistemological horizon of 'normal science': the only missteps that appear are those that can be retrospectively narrated through the linear ‘experiment $\rightarrow$ fail $\rightarrow$ adapt $\rightarrow$ learn $\rightarrow$ re-try $\rightarrow$ succeed' trajectory which results in 'inevitable' success. This singularized trajectory is further strengthened by the institutionalized structures of recognition that the scientists and engineers of Handhold labour under (e.g. promotion, more research funding, commercial rewards). You don't 
make full Professor with a litany of half-formed projects and unrealized ideas, despite the fact that the careers of all scientists and engineers - indeed, of all academics and scholars - are constituted by multiple mistakes that don't lead anywhere, dead-ends that produce no results, stupid ideas that sit in unopened files, and wasted efforts that produce feelings of shame and embarrassment. So while I want to draw attention to the widespread consensus over instructive failure that governed the work of Handhold's scientists and engineers, I also want to show that many other experiences of failure were always stubbornly present in ways that troubled the productive stories they were able to tell about the project.

This singularized account of instructive failure was also disrupted by the many different ways that each participant group understood failure, and how these competing views came into conflict. While all participants understood that the project as a whole would fail if they did not have a working prototype of the device at the halfway point (with the ultimate threat that the EU would pull funding), each professional culture operated under different understandings of failure that were often in competition with each other (MOBS7; SE1; SE2; SE4). For example, scientists and engineers based in university laboratories understood their own professional failure as not publishing original and innovative peer-reviewed work in top- quality journals with high impact factors. Conversely, those based in Small and Medium Enterprises (SMEs) understood failure as not effectively commercializing, spinning out or patenting a new product (SE9; SE15). The EU and UK managers coordinating research into security technologies had a very broad taxonomy of failure which included a device that lacked innovation, provided poor value for money, took too long to construct, did not result in widely disseminated research findings, and had limited impact in scientific and 
government circles (GOV1; GOV6; MREF2) ${ }^{2}$. These competing multiplicities of failure also emerged in technical negotiations over the device itself, for example, in discussions about sensor accuracy and how many false negatives or false positives would be tolerated (SE2). These very technical accounts of failure became the focus of obsessive discussions between scientists and engineers about thresholds - of what an acceptable level of failure might be (MOBS3; MOBS5). However, while scientists and engineers understood failure through highly granular and labile thresholds, end-users were very blunt about what constitutes failure: if a device cannot produce accurate, reliable and instantaneous readings, it is quickly discarded (ENDU1; ENDU2). Many times throughout the project, end-users jokingly referred to the legendary 'cabinets of horror' - the storage cupboards in customs depots, border crossings and industry headquarters all over the world that are full of detection technologies that have been enthusiastically acquired and then angrily rejected (SE1; MREF3; ENDU1).

Such diverse and competing understandings of failure were further mobilized through judgements about the quality of the research itself, often with reference to supposedly universal standards of what 'good quality' scientific research entails. For example, some of the technical work produced in advance of the prototype test was deemed to be 'disappointing' by some participants (MREF8), while the 'dummy data' provided by one work package (sensor development) to help speed up the progress of another (software) was seen as lacking and even 'half baked' (SE2; SE4; SE7; SE24). Often, complex negotiations over the sequencing of failure (e.g. 'if you can't get your sensor to work, then I can't build the necessary software') resulted in accusations that

\footnotetext{
${ }^{2}$ Given that all national, regional and international governing bodies adhere to well-established 9-stage 'Technology Readiness Levels' (TRLs), it would be interesting to trace the extent to which such a rigid taxonomy of device 'readiness' maps onto the instructive formation of failure discussed here (Horizon 2020, 2015).
} 
those at the latter end of the sequential chain (e.g. those waiting for dummy data or a hardware platform) were not 'pulling their weight' (SE4; SE10; SE11; SE15; MREF1; MREF6). This culture of judgement exacerbated the different cultural, national and institutional norms about when to admit that something was not working. For example, the early stages of each $\underline{\text { Handhold }}$ consortium meeting were characterised by partners hiding their lack of progress, or addressing difficulties only in terms of changing parameters of success. Failures, mistakes and accidents were only revealed in the more technical discussions later on when project leaders tried to bring the different aspects of the device together (MOBS3; MOBS4; MOBS5; MREF1).

When these multiple understandings of failure came into conflict through accusations and judgements, engineers often externalized the reasons and responsibilities for failure in highly inventive ways. Most often, failure was displaced out of the human realm and onto the device itself - failure was the fault of the technology, the recalcitrance of the basic materials (e.g. the chemicals), and the limitations of what scientific laws actually permit. If they were not blaming the device itself, $\underline{\text { Handhold }}$ scientists and engineers turned their attention to non-technical actors within the project. For example, during preparation for the prototype demonstration, the scientists and engineers gathered around the device - at that point the size of a large shoe-box - and recalled their initial claim that it would be small enough to 'fit in your pocket' or 'hang on your belt'. Whilst laughing at their own initial hubris, they were quick to claim that these early fantasies were the fault of funders and governments who (a) had unrealistic expectations of what the project could achieve; and (b) failed to understand the limits of the technologies and methods being deployed (MOBS6). In other words, 'it was their failure, not ours'. Similarly, failure was often displaced onto 
the non-expert end-user - in this case the border guard who was imagined as a rather undexterous, unintelligent, boorish figure who could not possibly understand how to ‘properly' use such a sophisticated technical device (MOBS6; Bourne, Johnson \& Lisle, 2015: 319-20). In a project relying on intense collaboration, however, these internal displacements of failure were repressed when co-operation was required in front of the EU funders (MOBS2; MOBS6; MOBS7). In these moments, failure was discussed only in relation to external actors; namely, the other portable 'sniffer-dog' projects funded under this EU scheme, or industry efforts to produce a similar device (SE1).

Amidst these efforts to displace, judge and compare, there was one figure that operated as an uncontested standard for failure: the actual sniffer dog (Bourne, Johnson \& Lisle, 2015: 319). Throughout the construction of the device, scientists and engineers often asked - sometimes rhetorically, but always with a great deal of concern - whether their sensor was faster, more accurate and more efficient than a living, working sniffer dog aiding customs and immigration agents at the border (MOBS4; MOBS7; ENDU1; MREF3). I found this anxiety intriguing because of the enormous force-from-a-distance these furry creatures exerted, and how that determined the thresholds of Handhold's sensors. There were many amusing moments when I witnessed world-leading scientists and engineers completely unravel when trying to match the sniffing capabilities of friendly cocker spaniels and Labrador retrievers. What struck me was how this 'perfect canine nose' could only work for the scientists and engineers if they isolated the dog's sniffing capacity from the complex, entangled and co-dependent choreography that actually unfolds when dogs work alongside customs and immigration officers at borders. In other border ethnographies I have done, it is clear that a dog's sensory capabilities operate in conjunction with the skills of the trainer, the dog-trainer 
relationship, the material infrastructure of the border itself (e.g. baggage belts; luggage retrieval areas), the pre-given data directing the search, and the institutional history of sniffer dog programmes (Treating People as Objects, 2016). What became clear in my observations of Handhold was that all these entanglements were effaced by the scientists and engineers' desire to isolate the nose of the dog as a static and quantifiable threshold against which they could judge the success or failure of their sensors. In other words, 'as long as we are better than an actual dog'.

What this complex sequencing of displacement, judgement, competition and projection reveals is that no matter how vigorously the consensus over instructive failure is policed, it is always disrupted by the diverse, unruly and often antagonistic experiences of failure that circulate through everyday scientific practice, professional cultures, technical discussions and partner negotiations. No matter how diligently the scientists and engineers of Handhold tried to obey the dictates of instructive failure, they could not extricate themselves from the messy, unordered and contingent nature of scientific research that includes non-productive, useless and tangential avenues of inquiry. No matter how diplomatically they tried to negotiate the competing thresholds of failure circulating between different professional cultures, these antagonisms actually informed the rate of progress and shaped the material components of the device itself. What this shows us is that to hold scientific research collaborations together, participants have to perform an instructive account of failure over and over again as a way to mask its contingency, disavow its non-productive formations and discipline competing understandings held by different actors. Indeed, that performance is central to failing better. 


\section{Speculative Failure: the informal practices of de-risking}

The scientists and engineers of Handhold tussled with the instructive account of failure governing the project through a mixture of obedience, performance, disruption and resistance which, at least initially, did not appear to be co-ordinated. However, as I observed their daily work and watched the idiosyncratic 'progress' of Handhold from idea to prototype, I began to notice very sophisticated strategies being used to mitigate against the device's potential failures. The Handhold participants revealed an acute awareness of the multiplicities of potential device failure, and through their informal practices of de-risking they demonstrated highly creative, adaptive and surprising ways to produce something recognizable as 'success'. That a lively world of failures was revealed through practices of de-risking should come as no surprise. Failure absolutely constitutes risk: it is the very thing to be avoided, and therefore the driving force of all forms of risk assessment, management and mitigation. We know, of course, that techniques of risk management are ubiquitous in modern life, and it is therefore unsurprising that Handhold's initial funding bid included an official strategy of riskmanagement. Here, the architects of the bid distinguished between technical risks that arise from working with dangerous substances (e.g. biological toxins; radioactive material) and social risks that arise from communicating classified material to geographically distant partners. These two risk categories were explicitly named in the bid document precisely because they were easily solved by well-established institutional safeguards and procedures. For example, the industry and university laboratories working with dangerous substances were already equipped with trained staff and the proper health and safety procedures to prevent technological failures (e.g. radiation, burns, contamination), and all participants understood the need to encrypt all data 
shared between partners to prevent the social risks of information leakage (e.g. classified material reaching 'the bad guys'). The familiarity of these risks, and the wellestablished methods of addressing them, meant that Handhold's official risk management strategy was both meaningless for the participants (i.e. the named procedures were already an established part of their daily practice), as well as useless in terms of specific guidance (i.e. it did not acknowledge the actual risks that emerged in the day-to-day development of the device). As many Handhold participants admitted, the official risk management strategy produced at the proposal stage was a 'form-filling exercise' that had very little impact on the project itself (GOV2; SE2).

This does not mean, however, that risk management was absent on the project. In the early stages of Handhold, I witnessed a very complex set of negotiations in which scientists and engineers navigated through the plural possibilities of risk and failure in the following way: by assuming that Plan A would undoubtedly fail, they constantly 'de-risked' by simultaneously working on multiple trajectories of research - not just Plan B, but also Plans C, D and E all at the same time. As one scientist / engineer explained, 'You cannot wait for it [Plan A] to fail' (SE8) but instead must proceed in one direction with multiple experimental trajectories constantly at work in the background. Certain partners even formalized this multiple-track approach by fully developing two different sensors at the same time, knowing full well that only one would eventually be used (SE18; SE19; SE21; SE15). Instead of the singular, ordered and highly focused story of scientific research retroactively produced by an instructive account of failure, I witnessed an official research plan (Plan A) that was highly provisional, and a very sophisticated process by which scientists and engineers tinkered with it, adapted it, and re-tooled it by incorporating aspects from the multiple research 
trajectories they were simultaneously developing (e.g. Plans B $\rightarrow$ E). I was struck by the energy, time and commitment that scientists and engineers gave to these alternative research trajectories: they were not neglected in the background as unloved second choices, but instead played an active role in shaping the research trajectory that the Handhold device eventually took. What most surprised me about these de-risking practices was the inexplicable way in which scientists and engineers arranged the best outcome from all these 'live' possibilities. As one scientist / engineer explained, this was not about rational calculation, but rather produced by 'gut feelings' and 'black magic' (SE23).

The clearest practice of de-risking involved decisions about whether to use mature or undeveloped technology in different aspects of the device. For example, many work packages relied on already well-established technologies in one area so that scientists and engineers were free to devote their attention to more 'risky' areas of research. Thus, Handhold participants agreed to use a reliable Open-Source operating system and a well-established computer chip - widely-used technologies that were easily adapted with the help of online communities - so they could pursue more innovative developments (SE2; SE5; MOBS1). Deploying mature technology as a derisking strategy was particularly clear in the sensor development process: most workpackages had 'off-the shelf' sensors ready for use in case the more innovative developments did not work (SE2). These negotiations between mature and undeveloped technology produced two surprising and highly imaginative accounts of failure. First, scientists and engineers offered a number of inventive, detailed and sometimes highly creative speculations about the possible reasons why a 'new' or 'old' sensor might fail (e.g. human error, blocked Wifi signal, dirt, temperature, moisture). These discussions 
continued at every phase of device development as they unearthed new possibilities for failure to add to the growing list (MOBS1; MOBS7). Second, these discussions about multiple potential failures were bounded by an energetic focus on the 'worst-case' scenario which was explored in great detail and with much intensity. This narrative was not the domain of the pessimist, but rather functioned positively to give structure to the numerous and proliferating possibilities of failure that the device generated. Trafficking between these two speculative imaginaries of failure revealed the scientists and engineers at their most flexible and adaptive. Complex discussions about (a) the increasing multiplicities of potential failure, and (b) the endlessly rich texture of the 'worst-case' scenario, actively informed their concrete decisions to get the sensors working and integrated into the device.

Those engagements with speculative failure became darker and much more ponderous when scientists and engineers acknowledged that some risks (and therefore some potential failures) are unknowable (SE2). Many times I witnessed complex disaggregations into known-knowns, unknown-knowns, known-unknowns, and the real problem, unknown-unknowns. I was impressed by the quiet and serious way the scientists and engineers acknowledged the presence of the unknown in their work: they may not know what to do about unknown-unknowns, but they recognize this category exists and they make room for it in their thinking and practice. For me, this respectful attunement to the unknown was the most palpable way that the scientists and engineers kept their research open to possibility, and in doing so, actively resisted an instructive account of failure. Indeed, the unknown never appears in the Dyson narrative's litany of instructive failures that prepare the ground for the eventual success. Recognizing the presence of the unknown threatens the progressive linearity of that story and disrupts its 
account of scientific practice as dogged, relentless graft in pursuit of a known and valuable goal (e.g. a bag-less vacuum cleaner). Certainly the Handhold scientists and engineers worked extremely hard, but their thoughtful musings about the unknown revealed how such labour is constituted by deep philosophical and existential reflection that cannot be stuffed into a sanitized story of scientific progress. For me, the $\underline{\text { Handhold }}$ participants' thoughtful considerations of the unknown exemplified the kind of 'unproductive' activities that get written out of the Dyson narrative.

Such existential musings about the unknown contrasted sharply with the frenzied predictions that dominated the lead up to Handhold's prototype demonstration (MOBS6). Despite a collective effort to de-risk for the day itself (including successful dry runs at the test site), scientists and engineers were frantically trying to predict what would go wrong during the demonstration, observe any potential risks they hadn't spotted, recalibrate probability, and invent pre-emptive explanations for what they felt would be inevitable failure. In these moments of high stress, there was no sense in which the demonstration would actually succeed; instead, all participants operated with an assumption that something would definitely go wrong. Indeed, while setting up_for the demonstration, a failure in software integration stopped the entire device from working - an unforeseen error which, thanks to the intense work of two researchers, was corrected before the EU funders arrived (MOBS6). What struck me about the prototype demonstration was how real failure was for everyone involved: it acted, influenced and changed behaviour. This was not the comfortable situation of 'failing better' in the safety of Silicon Valley, but instead a palpable fear that either they had not sufficiently imagined all the potential scenarios of device failure (which meant that something unforeseen would emerge during the test and embarrass everyone), or they had not 
successfully chosen the right (i.e. most instructive) pathway out of all the potential risks and failures identified (which meant that one of their alternative research trajectories from Plans B $\rightarrow$ E would suddenly emerge as the 'real' trajectory). At precisely the moment when the lively landscape of potential failures had to be contained in front of the project funders, they burst forth in the anxiety and panic of the Handhold participants. For me, there was something reassuring in the ill-timed appearance of failure's multiplicity at the prototype demonstration: for a brief period before the test, scientists and engineers were unable to perform failure as instructive. Instead, they were forced to inhabit the subterranean world of multiple, diverse and contradictory failures that felt threatening and uncontrollable rather than instructive.

As the Handhold project developed, I became interested in how these imaginative and sometimes uncomfortable practices of de-risking operated through tacit knowledge, assumed norms and shared understandings. Acknowledging Pink's (2015) warning that these silent atmospheres of affect, culture and non-verbal interaction are methodologically tricky to explore, I was able to sense some of their power in the way the expertise, experience, professional reputations and institutional positions of the Handhold participants shaped decisions about risk and failure. For example, those individuals with more experience (especially experience 'in the industry' as opposed to just academia) were considered better able to identify potential failures, judge their severity, and instigate de-risking practices. This reliance on the authority of a particular kind of expert to name and navigate potential failures is important because it reveals how wider constructions of power such as gender and seniority operate in collaborative research projects (GOV2). In Handhold, I reflected on these constructions of power as I observed how PhD students and Post-Doctoral researchers were (or were not) integrated 
into the informal, tacit and often unacknowledged way that potential risks and failures were navigated. In any institutional setting, hierarchical relationships of supervision and mentorship are one of the primary mechanisms through which tacit knowledge, assumed norms and shared understandings are transmitted, so if the mentoring relationship is not working, junior researchers might not pick up on informal understandings that seem so commonplace for more established researchers. In Handhold, I became interested in moments when the implicit understandings of risk and failure operative on the project were not shared - when the tacit, unspoken and inferred norms appeared to break down or were misunderstood by participants. For example, when a new target substance emerged part-way through the project there was a discussion as to which sensor would be responsible for its detection. Because senior scholars had the political, social and professional skills to avoid taking on such a risky last-minute addition, the task fell to an inexperienced team of junior researchers. When difficulties over this sensor inevitably emerged at a subsequent consortia meeting (i.e. when the spectre of failure reared its head) the junior researchers were heavily criticized. Unlike senior scholars, the junior researchers could not reassure the project participants that their wealth of experience would help them overcome these difficulties (MOBS3; MOBS4; MOBS6). I was struck by the skill with which senior researchers were able to mobilize tacit knowledge, assumed norms and shared understandings to avoid a difficult technological problem. This suggested that junior and more inexperienced researchers were not as effectively integrated into Handhold's silent register of shared perception, and were therefore unable to map their specific understandings of risk and failure onto those operative in the wider project. The problem, here, is that the stakes for junior researchers are potentially career-ending. 
Unlike senior scholars who can weather reputational damage, the failure of a whole project means that PhD students are at risk of failing their Viva exams, and PostDoctoral scholars are at risk of having their funding cut and their positions discontinued.

I was not surprised by the lack of force exerted by Handhold's formal risk management strategy outlined in the bid: risk management as a technique of governance has become so institutionalized that it bears no resemblance to the actual risks that arise in everyday working practices. But what did surprise me was the force with which more heterogeneous understandings and experiences of failure made themselves felt, particularly through informal de-risking practices and during the stressful preparation for the prototype demonstration. These examples suggest that the single trajectory of 'experiment $\rightarrow$ fail $\rightarrow$ adapt $\rightarrow$ learn $\rightarrow$ re-try $\rightarrow$ succeed' underscoring the Dyson narrative (i.e. what is retrospectively told as an uncontested Plan A) is only ever constituted by a multiplicity of alternative trajectories that are kept alive throughout the development phase (i.e. Plans $\mathrm{B} \rightarrow \mathrm{E}$ ). More to the point, which bits end up populating the final trajectory of the device (Plan A) and which bits don't (Plans B $\rightarrow \mathrm{E}$ ) is not the result of calculated and inflexible risk management protocols. Rather, 'success' is much more about the creative, speculative and highly imaginative art of de-risking than it is about linear and logical scientific discovery.

\section{Re-Routing Failure: the detours of creativity and innovation}

Unlike the scientists and engineers who responded to my queries about failure with confusion and avoidance (SE1, SE2, SE6, SE7, SE8), the EU and UK government 
figures involved in exploring science in a security context offered highly reflexive accounts of what failure is, what it means, and how we might understand it better. ${ }^{3}$ More comfortable thinking about success rather than failure, they often framed discussions about technology development with thoughtful ruminations about 'what counts as good', 'what does good look like?', and 'what counts as good enough?' (GOV1) For me, one of the most intriguing statements from a government figure was a rather forlorn observation that scientists and engineers were not very good at failure: 'we have failed to specify what failure is', and more importantly, 'we don't learn our lessons well' (GOV6). Unlike the Handhold scientists and engineers who struggled to interpret my interest in failure, senior government figures welcomed efforts to think more specifically, coherently and deeply about it. While I was initially excited by provocative challenges such as 'what is failure composed of?' (GOV6), I quickly realized that these questions were always posed instrumentally: the goal was to make scientists and engineers better at failure by teaching them to learn the right lessons in the right ways (i.e. isolating and encouraging only 'instructive' forms of failure). On reflection, this instrumental approach was apparent in the tone of lament that framed their philosophical musings (i.e. why are we so bad at this? Why don't we understand it?) What I came to realize in these interactions was that government figures were actively and enthusiastically reproducing precisely the problem I was trying to expose that instructive forms of failure are limiting and depoliticizing because they preemptively constrain what it is possible to know, learn and discover.

\footnotetext{
${ }^{3}$ By 'government figures' here, I mean the EU scientists, engineers and managers who had oversight for all the scientific consortia, including Handhold, that were funded under the Horizon 2020 scheme, as well as the UK-based scientists and engineers based in the Defence Science and Technology Laboratory (DSTL) who were directly involved in all the projects funded under the ESRC's Science and Security theme and who liaised directly with our TRUST project.
} 
Of particular interest for me was the way government figures sought to frame instructive failure in entrepreneurial terms. All Handhold participants and managers understood themselves to be playing 'catch up' with small start-ups and big tech corporations who operate with a 'fail fast, fail early, fail often' mind set. Indeed, UK government figures were unapologetic about their need to learn big tech's focus on creativity, innovation, collaboration, experimentation and 'blue-skies thinking' as a way to harness failure's productive capacities (GOV1; GOV2; GOV3; GOV4). Absolutely central to this understanding is the belief that instructive failure produces innovation. Indeed, UK government figures recognize that the traditionally inflexible institutional settings of scientific research and development make it very difficult to explore the creative avenues that lead to innovation, in part because of a pervasive fear of failure. For this reason, they are developing more 'risk-free' opportunities and 'safe spaces' for researchers to pursue creative impulses, indulge hunches, think laterally ('outside the box') and imagine technology outside of its normal limitations without the threat of destroyed reputations or career demotion (GOV3; GOV4). These figures spoke animatedly and excitedly about the kinds of innovations that might result if creative thinking were allowed to flourish openly in the laboratory (GOV3; GOV4; GOV6). Throughout all this energetic talk, it became clear that a constitutive tension lay at the heart of this pursuit of innovation: on the one hand, it is necessary to foster creative thinking because this will eventually produce the kind of instructive failure that leads to innovation; on the other hand, fostering creative thinking is risky because it produces so many non-productive failures that never result in innovation. What about all those creative endeavours that remain on the laboratory floor? Is it really OK to produce that 
much failure in the pursuit of innovation? Or is there a threshold where too much failure cannot be sustained?

For me, these non-productive failures left in the wake of 'successful' innovation

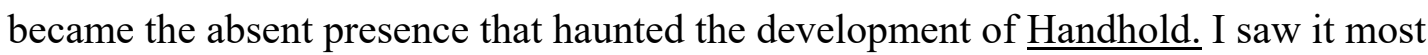
clearly when scientists and engineers revealed how much pressure they felt to produce innovative research, and the mixture of apprehension and terror they felt at the possibility that their research would be pointless because it did not lead to anything new or ground-breaking. This burden of innovation shaped all participants who expended enormous energy trying to make their part of the device more 'cutting edge' in

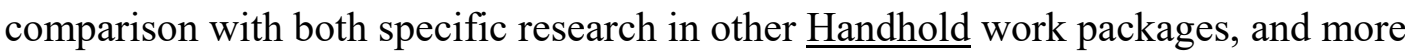
general research in their particular scientific field (e.g. optics; software; sensors) (SE9; SE15; SE19; SE21; SE22; MOBS1; MOBS4). For me, this pressure is indicative of a much wider (and much more concerning) transformation in which the drive for innovation requires a wholesale capture of the contingent and often haphazard process of knowledge production. Any idea, hunch, tangent, daydream, distraction, playful moment, lapse of focus or spontaneous interaction is coded in advance as potentially creative, and thus has the capacity to produce an instructive failure that will lead to innovation. Here, failure is both everywhere and nowhere: if every creative impulse is potentially an instructive failure that will result in innovation, then it cannot be considered a failure.

What concerns me about this drive for innovation is how big tech companies (and the governments and universities chasing them) are using it to transform the norms of everyday scientific practice in ways that strip practitioners, experts, students and scholars of their agency. For example, in order to capture the lucrative potential of 
instructive failure, big tech companies must put the entire lives of their employees under surveillance because creative impulses could arise anywhere, at any time. The pernicious reach of this creativity-failure-innovation nexus is exemplified by the Googleplex campus in Mountain View California where there are free meals, free haircuts, swim-in-place pools, games rooms, pianos, a gym and sleep pods. These 'perks' encourage employees to spend more and more of their non-labouring life in the Googleplex so they can increase 'creativity and teamwork'. But as Fuchs \& Trotter (2013:38-39) argue, this 'playification of work' and 'workification of play' mean that the Googleplex operates like a giant laboratory where every idea, behaviour and interaction is constantly under surveillance by a company that mines its employees' creative impulses 24/7 (see also Fuchs, 2011). To identify those embryonic ideas that will most likely result in instructive failure (and therefore lucrative innovation), Google creates the conditions for unscripted events to occur (e.g. an off-hand comment during a table tennis game; a 'eureka' moment on a treadmill; a dream in a sleep pod), and then captures, develops and hopefully monetizes them. Because these events emerge in the domains of leisure, relaxation, self-care and everyday life (rather than during the repetitive grind of routine coding), Google creates the conditions in which all aspects of an employee's life are available for the company to access, develop, utilize and own. Indeed, the price of working at one of the world's biggest tech firms is total surrender: all your ideas, behaviours and interactions are pressed into service supporting Google's relentless search for creative thinking and instructive failure which they can turn into lucrative innovation (Ross, 2015; Walker, 2011)

How are we supposed to think about failure when every single idea, hunch or tangent is coded in advance as potentially innovative? Who decides which ideas have 
the capacity to be instructive failures and therefore ripe for innovation, and which are considered non-productive, irrelevant and useless? The recent interest in failure by governments and universities appears inclusive because it makes failure ubiquitous: all creative ideas - even the craziest and most likely to fail - are valid because they might lead to instructive failure that will eventually result in innovation. In this context, it appears that failure has been made impossible: it has completely disappeared from the epistemological horizon. If something doesn't work, or mistakes are made, or collaborations fall apart - all these can be written off as failed efforts to innovate. But what this inclusive tone masks, of course, is the emergence of a new consensus that forces all scientific endeavour - even the most speculative - to be explicitly productive. In other words, you cannot fail for failure's sake: you must fail in the service of innovation. What this does, of course, is constrain creative thinking in precisely the ways that were supposed to be avoided. 'Thinking outside the box' is the new norm: it is contained within a newer, shinier and more entrepreneurial box labelled 'innovation' which is much more pernicious than its predecessors because it operates through the frames of openness, inclusivity and diversity. This attachment of instructive failure to the pathway of innovation is extremely problematic because it limits those possibilities of research deemed to be most speculative and cutting-edge. The result of this capture is that we are unable to explore whether alternative experiences of failure - those that are not explicitly productive - might lead to a different kind of innovation altogether.

\section{Unlearning Failure:}

What became clear in the development of the Handhold device was that the difficult, awkward, painful experiences of failure that could not be handcuffed to the 
progressive narrative of 'experiment $\rightarrow$ fail $\rightarrow$ adapt $\rightarrow$ learn $\rightarrow$ re-try $\rightarrow$ succeed' were disavowed in a way that reduced failure to mere utility. Failure was only 'instructive' when it resulted in success, and more importantly, innovation. This narrowly instrumental way of understanding failure stems, in part, from an over-reliance on traditional scientific methods of quantification. Failure is something to be isolated, captured, disaggregated, measured, managed and put to work, which requires the kind of dispositions that are capable of instrumentalizing the world in this way. I witnessed the force of this thinking in the wide-spread consensus within Handhold about the kinds of instructive failures that would enable participants to reach their agreed goal of creating an innovative portable security device that would help stop the movement of dangerous substances across borders. While this consensus required participants to ignore, displace or jettison the difficult, awkward and unruly experiences of failure that did not directly contribute to this goal, they were ultimately unable to do so. Indeed, the project was haunted by all those uncomfortable and useless failures that littered their laboratories, intensified their anxieties, and kept disrupting their efforts to secure a clean and progressive pathway from instructive failure $\rightarrow$ success.

I want to argue that by paying closer attention to those disavowed experiences of failure that I saw haunting the construction of the Handhold device, we can start to unlearn this dominant trajectory of instructive failure that constrains scientific research. The first step in this unlearning process is to engage more intensely with STS thinkers who open up vital intellectual spaces where the multiplicities of failure can be studied in the context of a wider critical re-imagining of science. For example, does the complex world of failure I discovered on the Handhold project align with Parisi's (2013) formulation of error, indeterminacy and blind spots that constitute algorithmic decision 
making? Do my observations about the speculative imaginaries of de-risking speak to ideas about uncertainty within Quantum theory, and could this help us re-calibrate the reductive success / failure logic (Barad, 2007; Stengers, 2011)? For me, STS's deconstruction of the objectivity and instrumentality of science is a necessary starting point if we are to further trouble the Dyson narrative and discover all the other lively forms of failure that operate during scientific thinking and practice. The second part of this unlearning process involves paying more attention to the critical explorations of failure that have been developing in the creative arts. For curator Lisa Le Feuvre (2010: $13,19)$ a much richer, deeper and more vibrant account of failure has been animating visual artists for decades:

When failure is released from being a judgemental term, and success deemed overrated, the embrace of failure can become an act of bravery, of daring to go beyond normal practices and enter a realm of not-knowing... In this uncertain and beguiling space, between the two subjective poles of success and failure, where paradox rules, where transgressive activities can refuse dogma and surety, it is here, surely, that failure can be celebrated (see also Buckley, 2015).

From this starting point, my engagements with the Handhold project can be understood as a process of uncovering how this 'uncertain and beguiling space' played a constitutive part in the development of the device. Given that every aspect of the scientific research process was about closing this space down, disavowing it and moving forward in a singular, linear and progressive fashion, it is unsurprising that I found this much more difficult than I had initially expected. 
In the clinical, ordered and calculative world of science, what is written out of the Dyson narrative is failure's emotional punch, what Werry \& O'Gorman (2012: 106) describe as the 'familiar, bleak, heavy vacancy, that bottom-punched-out-of-my-world emptiness.' Failure is painful - it is awful and agonizing and can't easily be put into words - which is why it is so quickly disavowed and replaced by the highly disciplining practices of rational calculation, mature deliberation and 'gentlemanly' consideration. By acknowledging failure in all its awful, painful and uncontrollable fury, these creative imaginings help disaggregate it into its many different emotional components (e.g. shame, embarrassment, disgrace, vulnerability, humiliation and exposure). At the Institute of Failure, a collective that includes thinkers from the fine arts, economics, computing, architecture and performance, failure is always understood in its multiplicity: at a minimum, it is constituted by 26 alternative states including Uselessness, Embarassment, Incoherence, Absurdity and Distractability’ (Etchells \& Goulish, 2001). I found this disaggregation enormously helpful as I tried to puzzle

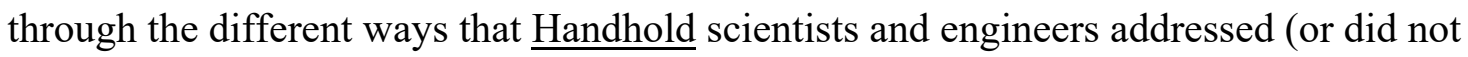
address) the emotional landscape of failure. Certainly there was anxiety about damaged reputations and career advancement, but there was also shame and embarrassment over lack of progress, aggressive forms of projection and displacement, and melancholy articulations of futility. None of this, of course, is captured by the supposedly resilient scientist who reflects rationally on her errors, learns from her mistakes and produces successful adaptations. In performing the Dyson narrative, this scientist might also feel shame, panic, paranoia helplessness, despair and humiliation, but none of these are represented in the final story. What is also absent from that singular narrative is the possibility that failure might be a pleasurable experience. As Nick Ridout (2006: 77-79) 
has explained with respect to the failures of theatre, audiences secretly want something to go wrong on stage so they can fully experience the affective resonance of a live performance. When the bourgeoisie norms of theatre fall apart - when animals don't behave, when someone gets stage fright, when an actor 'corpses' or gets the giggles the resulting excitement and anxiety on the part of the audience becomes a perverse kind of anticipated pleasure (Ridout, 2006: 71). Given the apparent ubiquity of failure in the everyday work of the Handhold scientists and engineers, I began to wonder whether they actually enjoyed the ever-present sensations of collapse, crisis, panic and chaos.

Paying attention to the multiple emotional states of failure is important because it disrupts and re-orders the linear temporality of the Dyson narrative. Instructive failure assumes that a chosen trajectory of research is rationally arrived at and fully executed before it fails and undergoes adaptation. None of this forward-moving energy explains the failure to produce anything at all, or the discarded projects that never get off the ground. Artist Tim Etchells explores these embryonic failures in his long running collection of 'Apologies and Un-Made' shows: 'a performative graveyard for failed, unproductive and unworkable ideas' (Etchells, 2002). Similarly, Sarah Jane Bailes $(2002 ; 2010)$ uses the experience of distraction - of being taken away from the task at hand - to reflect on the feelings of underachievement that emerge in the distance between your dream and your failure to achieve it. Along with considering those embryonic and aborted failures, creative artists also help us extend the duration of failure's occurrence so we can rest awhile in its painful grasp. If we are serious about contesting the relentless drive to only fail instructively, then we need to forcibly extend the duration of failure's painful occurrence for longer than is normal or necessary. Inhabiting the 'heavy vacancy' of that painful duration is important because it prevents 
the easy retrospective narration of failure as a necessary 'hiccup in a predetermined route to success' (Leese, 2015: 277). When failure refuses such a predetermined route and holds open the ground for alternative possibilities, it becomes an important political experience in its own right. This is precisely the purpose of the Institute of Failure who recast the story of human failure as 'a kind of unspeakable beauty' (Heathfield, 2001) that is both stubbornly permanent and irresolveable. Creative writers are particularly helpful here as they speak openly about how it feels to live with failure everyday. Novelist Anne Enright, for example, claims that 'failure is what writers do. It is built in'; Will Self goes one step further in claiming that 'all political lives end in failure, but all writing ones begin there, endure there, and then collapse into senescent incoherence' (The Guardian, 2013: 4). What most energizes me about these creative re-imaginings of failure is their ability to bring back the original dark intent of Beckett's claim to 'fail better' - an intent that can never be sanitized by shiny management slogans or entrepreneurial rhetoric. As novelist Ned Bauman (2012) brilliantly explains: 'Watching a liturgy from such a gloomy and merciless author getting repurposed to cheer up midlevel executives is like watching a neighbour clear out their gutters with a stick they found in the garden, not realizing the stick is in fact a human shinbone'. I came to see my explorations of $\underline{\text { Handhold }}$ as a kind of critical paleontology: digging up the shinbones of unwanted failure that the scientists, engineers and managers kept burying.

\section{Failing Worse:}

During my observations of the Handhold device, I read Allegra Goodman's novel Intuition (2006) which explores how usually unspoken emotions emerge in the carefully regimented space of a cancer research lab. She exposes the human dramas that 
unfold when an experiment with initially exciting results gradually implodes and results in failure. Goodman's narrative spends a great deal of time in the laboratory itself, and shows how routine decisions made by scientists are shaped by a rich emotional landscape of excitement, doubt, envy, boredom, camaraderie, competition, lust, fear, exhaustion, isolation and distress. The denouement of the story is absolutely not about redemption or success, but instead involves the dismantling of a world-renowned laboratory team engulfed in disappointment, betrayal and failure. By usual narrative standards Goodman's story is a tragedy, but I found it hugely inspirational precisely because she lets readers - especially non-scientists - see what we don't usually see in conventional stories about scientific discovery. I am in no doubt that reading Goodman's story shaped my own observations of the Handhold project, forced me to consider what remains hidden during the process of technology development, and gave me the confidence to ask rather unorthodox questions about the experience of failure in that process. Indeed, it was only by listening to insights from more explicitly creative formations like Goodman's that I was able to see the powerful work that instructive failure was doing as the Handhold device was being constructed. On closer inspection, it became clear that failure really did have a life of its own in the Handhold project - a very rich, often circuitous and thoroughly poly-vocal life that refused to be fully disciplined or disavowed. No matter how powerful or comprehensive the attempts to make failure serve the pre-determined goals of success, it always slipped out from underneath. Paying attention to those slippages opened up a subterranean register of failure that was emotionally rich, temporally complex and sometimes painfully unruly.

While this paper works through the particular case study of how failure operated on the Handhold project, it gestures to a number of issues that emerge in the 
intersections of science, security and border technologies that require further investigation. First, the critical intent of this paper has been to demonstrate how an instructive account of failure governs scientific practice. While I have shown how the Dyson narrative is disrupted by more heterogeneous experiences of failure, I think more dedicated work is needed to specify, focus and develop the substance and texture of that heterogeneity. For example, are there more common forms of uselessness? Does a lack of productivity require particular affective attunements and emotional dispositions? When does uselessness emerge and disappear? Second, within the field of Critical Security Studies, we know that failure is constitutive of all types of risk analysis, assessment and management, but more work is needed to understand the tensions between risk and failure, how pre-emption and precaution govern the temporalities of failure (especially in the antecedent space of the laboratory), and whether non-rational, un-calculable and creative understandings of failure might reveal the limitations of risk analysis more acutely. Third, a great deal more critical attention is needed to show how the relentless pursuit of innovation curtails academic freedom, limits epistemological horizons, instrumentalizes knowledge production and disciplines the bodies, minds and behaviours of knowledge producers. Although I have argued for an enthusiastic engagement with critical STS scholars and creative artists who help us re-imagine failure, I worry that the same forces that have co-opted the energetic capacities of innovation will soon do the same to these fertile spaces of critical thinking. With this in mind, we need to be even more determined in revealing those multiple and often unruly experiences of failure that refuse to be made productive within the epistemological horizon of scientific research. All of this, of course, has implications for the decisions that are eventually made at the border with the aid of security technologies like 
Handhold. I consider this intervention as a hopeful starting point that brings the antecedent register of security technology development into critical focus. What is needed are further explorations of how the closed logic of success / failure underscoring the Dyson narrative amplifies and strengthens the norm / deviant logic governing technologized border decisions. Does this alignment exacerbate pre-existing social exclusions such as race, gender, class and sexuality? How does the force of this alignment intensify at different parts of the border assemblage (e.g. the laboratory; the Cloud; the visa office; the border crossing)? Which bodies and objects disproportionately 'fail' to be included in the pre-generated category of normal? Where do deviations occur most frequently, where do they disappear, and who is affected by this? As this paper has argued, one way we can politicize failure in that elongated border space is to pay closer attention to the poly-vocal and heterogeneous experiences of failure that disrupt, contest and un-work reductive in/out border decisions. In our interrogations of border security technologies, then, we should not uncritically accept the sanitized stories of failing better; rather, we should have the courage to explore stories of failing worse in order to see what epistemological, material and political horizons they open up.

\section{References}

Amicelle, Anthony; Aradau, Claudia \& Jeandesboz, Julien (2015) 'Questioning Security Devices: Performativity, Resistance, Politics', Security Dialogue, 46(4): 293-306. 
Amoore, Louise (2013) The Politics of Possibility: Risk and Security Beyond Probability. Durham: Duke University Press.

Amoore, Louise (2011) 'Data Derivatives: On the Emergence of a Security-Risk Calculus for our Times', Theory, Culture \& Society, 28(6): 24-43.

Amoore, Louise (2009) 'Algorithmic War: Everyday Geographies of the War on Terror', Antipode, 41(1): 41-69.

Amoore, Louise \& Raley, Rita (2017) 'Securing with Algorithms: Knowledge, decision, sovereignty', Security Dialogue, 48(1): 3-10.

Amoore, Louise \& Piotukh, Volha, eds. (2016) Algorithmic Life: Calculative Devices in the Age of Big Data. London: Routledge.

Amoore, Louise \& Hall, Alex (2009) 'Taking People Apart: Digital dissection and the body at the border', Environment and Planning D: Society and Space, 27(3): 444-464.

Aradau, Claudia \& Blanke, Tobias (2015) 'The (Big) Data-Security Assemblage: Knowledge and Critique', Big Data and Society, 2(2): 1-12.

Bailes, Sarah Jane (2010) Performance Theatre and the Poetics of Failure. London: Routledge.

Bailes, Sarah Jane (2002) 'Distracted', Institute of Failure, available at http://www.institute-of-failure.com/distracted.html (19/09/14)

Barad, Karen (2007) Meeting the Universe Halfway: Quantum Physics and the Entanglement of Matter and Meaning. Durham, NC: Duke University Press. 
Basulto, Dominic (2012) 'The New Fail\#: Fail Fast, fail early and fail often', Washington Post, 30 May, available at http://www.washingtonpost.com/blogs/innovations/post/the-new-fail-fail-fastfail-early-and-fail-often/2012/05/30/gJQAKA891U blog.html (accessed $15 / 09 / 14)$

Bauman, Ned (2012) 'Fail Worse', New Inquiry, 9 February, available at http://thenewinquiry.com/essays/fail-worse/ (accessed 15/09/14)

Baumard, Philippe \& Starbuck, William H. (2005) 'Learning from Failures: Why it May Not Happen', Long Range Planning (special issue on Organizational Failure), 38(3): 281-298.

Beckett, Samuel (1984) Worstward Ho. London: John Calder.

Bourne, Mike; Johnson, Heather \& Lisle, Debbie (2015) 'Laboratizing the border: The production, translation and anticipation of security technologies', Security Dialogue, 46(4): 307-325.

Browne, Simone (2010) 'Digital Epidermalization: Race, Identity and Biometrics', Critical Sociology, 36(1): 131-150.

Cannon, Mark D., \& Edmondson, Amy C. (2005) 'Failing to Learn and Learning to Fail (Intelligently): How Great Organizations Put Failure to Work to Innovate and Improve', Long Range Planning (special issue on Organizational Failure), 38(3): 299-319.

Daily Motion (2011) 'Samuel Beckett - Try Again, Fail Again, Fail Better’, Daily Motion, $6^{\text {th }}$ July, available at 
https://www.dailymotion.com/video/xjqonm_samuel-beckett-try-again-failagain-fail-better-liam-neeson creation $\% 23$ from=embediframe (accessed $15 / 09 / 14)$

De Goede, Marieke \& Samuel Randalls (2009) 'Precaution, Preemption: arts and technologies of the actionable future', Environment and Planning D: Society and Space, 27(5): 859-878.

Dyson, James (2014) ‘2,000 Dysons Later’, available at https://dublin.sciencegallery.com/failbetter/2000dysonslater (accessed 19/09/14)

ENDU1 (2013) TRUST Interview with End User, 18/11/13.

ENDU2 (2013) TRUST Interview with End User, 18/11/13.

Etchells, Tim (2002) 'The Small Failures', The Institute of Failure, available at http://www.institute-of-failure.com/smallFailures.html (accessed 19/09/14)

Etchells, Tim \& Goulish, Matthew (2001) The Institute of Failure, available at http://www.timetchells.com/projects/curatorial-projects/institute-of-failure/ (accessed 19/09/14.

Firestein, Stuart (2015) Failure: Why Science is so Successful. New York: Oxford University Press.

FOBS3 (2013) TRUST Observations of Participating Laboratory, 08/11/13.

Fuchs, Christian (2011) 'A Contribution to the Critique of the Political Economy of Google', Fastcapitalism, 8(1), available at 
http://www.uta.edu/huma/agger/fastcapitalism/8_ 1/fuchs8 1.html (accessed $15 / 08 / 16)$

Fuchs, Christian \& Trotter, Daniel (2013) 'The Internet as Surveilled workplayplace Factory', pp. 35-57 in Serge Gutwirth, Ronald Leenes, Paul de Hert and Yves Poullet, eds. European Data Protection: Coming of Age. Dordrecht: Springer.

Goodman, Allegra (2006) Intuition. New York: Random House.

Hall, Alex (forthcoming) 'Decisions at the Data Border: Discretion, Discernment and Security', Security Dialogue.

Handhold (2012) Handhold, available at www.handhold.eu (accessed 16/09/14)

Haraway, Donna (2016) Staying with the Trouble: Making Kin in the Chthulucene. Durham, NC: Duke University Press.

Harvey, David (2007) 'Neoliberalism as Creative Destruction', Annals of the American Academy of Politics and Social Science, 610(1): 21-44.

Heathfield, Adrian (2001) 'Introduction to the Launch of the Institute of Failure', Institute of Failure, available at http://www.institute-offailure.com/adrianIntro.html (accessed 19/09/14)

Horizon 2020 (2014) ‘Appendix G: Technology readiness levels (TRL)’, Horizon 2020 - Work Programme 2014-2015, available at http://ec.europa.eu/research/participants/data/ref/h2020/wp/2014_2015/annexes/ h2020-wp1415-annex-g-trl_en.pdf (accessed 07/10/16) 
Latour, Bruno (1987) Science in Action: How to follow scientists and engineers through society. Harvard: Harvard University Press.

Latour, Bruno \& Woolgar, Steve (1979) Laboratory Life: The Construction of Scientific Facts. London: Sage.

Leese, Matthias (2015) '’We Were Taken by Surprise': body scanners, technology adjustment, and the eradication of failure', Critical Studies on Security, 3(3): 269-282.

Magnet, Shoshana (2011) When Biometrics Fail: Gender, Race and the Technology of Identity. Durham, NC: Duke University Press.

MOBS1 (2013) TRUST Observations of HANDHOLD Consortium Meeting, 09/05/13.

MOBS2 (2013) TRUST Observations of HANDHOLD EU Review Meeting, 10/05/13.

MOBS3 (2013) TRUST Observations of HANDHOLD Consortium Meeting, 24/09/13.

MOBS4 (2014) TRUST Observations of HANDHOLD Technical meeting, 03/03/14.

MOBS5 (2014) TRUST Observations of HANDHOLD Consortium Meeting, 15/04/14.

MOBS6 (2014) TRUST Observations of HANDHOLD Demonstration and Review, $16 / 04 / 14$.

Mol, Anne-Marie (2003) The Body Multiple: Ontology in Medical Practice. Durham, NC: Duke University Press.

MOBS7 (2014) TRUST Observations of HANDHOLD Integration Meeting, 15/07/14.

MREF1 (2013) TRUST Reflections on Group Meeting, 31/05/13. 
MREF2 (2013) TRUST Reflections on meeting with DSTL Technical Partner, 10/06/13.

MREF3 (2013) TRUST Reflections on Group Meeting, 17/06/13.

MREF5 (2014) TRUST Reflections on Group Meeting, 28/02/14.

MREF6 (2014) TRUST Reflections on Group Meeting, 20/05/14.

MREF8 (2014) TRUST Reflections on Group Meeting, 01/05/14.

O’Connell, Mark (2014) ‘The Stunning Success of 'Fail Better': How Samuel Beckett became Silicon Valley’s Life Coach' Slate.com, 29 January, available at http://www.slate.com/articles/arts/culturebox/2014/01/samuel beckett s quote fail_better_becomes the mantra_of_silicon_valley.html (accessed 15/09/14)

Pink, Sarah (2015) Doing Sensory Ethnography, $2^{\text {nd }}$ ed. London: Sage.

Ross, Alastair (2015) 'Why did Google abandon 20\% time for innovation?' HR Zone, $3^{\text {rd }}$ June, available at http://www.hrzone.com/lead/culture/why-did-googleabandon-20-time-for-innovation (accessed 15/08/16)

Salter, Mark (2014) 'Everyday Failure: The Measure of Security Screening Machines' paper presented at the 'Securities and Mobilities' workshop, University of Amsterdam, 25/09/14

Schumpeter (2011) 'Fail Often, Fail Well: Companies have a great deal to learn from failure - provided they manage it successfully', The Economist, 14 April, available at http://www.economist.com/node/18557776 (accessed 15/09/14) 
Science Gallery (2014) Fail Better (Exhibition), Trinity College Dublin, available at https://dublin.sciencegallery.com/failbetter (accessed 15/09/14)

SE1 (2013) TRUST Interview with HANDHOLD Scientist / Engineer, 16/09/13.

SE2 (2013) TRUST Interview with HANDHOLD Scientist / Engineer, 16/09/13.

SE4 (2013) TRUST Interview with HANDHOLD Scientist / Engineer, 24/10/13.

SE5 (2013) TRUST Interview with HANDHOLD Scientist / Engineer, 24/10/13.

SE6 (2013) TRUST Interview with HANDHOLD Scientist / Engineer, 24/10/13.

SE7 (2013) TRUST Interview with HANDHOLD Scientist / Engineer, 28/10/13.

SE8 (2013) TRUST Interview with HANDHOLD Scientist / Engineer, 28/10/13.

SE9 (2013) TRUST Interview with HANDHOLD Scientist / Engineer, 07/11/13.

SE10 (2013) TRUST Interview with HANDHOLD Scientist / Engineer, 07/11/13.

SE11 (2013) TRUST Interview with HANDHOLD Scientist / Engineer, 07/11/13.

SE15 (2013) TRUST Interview with HANDHOLD Scientist / Engineer, 08/11/13.

SE18 (2014) TRUST Interview with HANDHOLD Scientist / Engineer, 08/04/14.

SE19 (2014) TRUST Interview with HANDHOLD Scientist / Engineer, 08/04/14.

SE21 (2014) TRUST Interview with HANDHOLD Scientist / Engineer, 08/04/14.

SE22 (2014) TRUST Interview with HANDHOLD Scientist / Engineer, 09/04/14.

SE23 (2014) TRUST Interview with HANDHOLD Scientist / Engineer, 28/05/14. 
SE24 (2014) TRUST Interview with HANDHOLD Scientist / Engineer, 28/05/14.

Stengers, Isabelle (2011) Cosmopolitics II, Trans. Robert Bononno. Minneapolis: University of Minnesota Press.

Stengers, Isabelle (2010) Cosmopolitics I, Trans. Robert Bononno. Minneapolis: University of Minnesota Press.

Stengers, Isabelle (2000) The Invention of Modern Science, Trans. Daniel W. Smith. Minneapolis: University of Minnesota Press.

Stengers, Isabelle (1997) Power and Invention: Situating Science, Trans. Paul Bains. Minneapolis: University of Minnesota Press.

Tracing Risk and Uncertainty in Security Technologies (TRUST) (2013) Tracing Risk and Uncertainty in Security Technologies, ES/K011332/1, available at http://www.esrc.ac.uk/my-esrc/grants/ES.K011332.1/read (accessed 16/09/14)

Treating People as Objects (2016) Treating People as Objects: Ethics, Security and the Governance of Mobility, ESRC Project Reference ES/L013274/1, available at http:/gtr.rcuk.ac.uk/projects?ref=ES/L013274/1 (accessed 16/07/17).

Vallery, Tenaya K. (2016) 'Growth from Failure’, Science, 353(6298): 514.

Vukov, Tamara (2016) 'Target Practice: the algorithms and biopolitics of race in emerging smart border practices and technologies', Transfers, 6(1): 80-97.

Walker, Abe (2011) 'Creativity loves constraints': The paradox of Google's twenty percent time' ephemera: theory \& politics in organization, 11(4): 369-386, 
available at http://www.ephemerajournal.org/sites/default/files/11-4walker.pdf (accessed 15/08/16)

Wilcox, Lauren (2015) Bodies of Violence: Theorizing Embodied Subjects in International Relations. Oxford: Oxford University Press.

Zaringhalam, Maryam (2016) 'Failure in Science is Frequent and Inevitable - and We Should Talk More about It', Scientific American, $30^{\text {th }}$ June, available at $\underline{\text { http://blogs.scientificamerican.com/guest-blog/failure-in-science-is-frequent- }}$ and-inevitable-and-we-should-talk-more-about-it/ (accessed 10/09/2016). 